\section{(2) OPEN ACCESS}

- Additional material is published online only. To view please visit the journal online (http://dx.doi.org/10.1136/ gutjnl-2019-318440).

For numbered affiliations see end of article.

Correspondence to Dr Sanjay K Murthy, Department of Medicine, The Ottawa Hospital, University of Ottaw, Ottawa, Ontario K1H 8L6, Canada; smurthy@toh.ca

Received 2 February 2019 Revised 23 April 2019 Accepted 23 April 2019 Published Online First 12 June 2019
Check for updates

(C) Author(s) (or their employer(s)) 2020. Re-use permitted under CC BY-NC. No commercial re-use. See rights and permissions. Published by BMJ.

To cite: Murthy SK, Begum J, Benchimol El, et al. Gut 2020;69:274-282

\title{
Introduction of anti-TNF therapy has not yielded expected declines in hospitalisation and intestinal resection rates in inflammatory bowel diseases: a population-based interrupted time series study
}

\author{
Sanjay K Murthy (D) , ${ }^{1,2,3,4}$ Jahanara Begum, ${ }^{5}$ Eric I Benchimol (D) , 4,5,6,7,8 \\ Charles N Bernstein, 9,10 Gilaad G Kaplan (D) , ${ }^{11,12}$ Jeffrey D McCurdy, 1,2,3 \\ Harminder Singh, 9,10 Laura Targownik, ${ }^{9,10}$ Monica Taljaard ${ }^{3,4}$
}

\section{ABSTRACT}

Objectives To better understand the real-world impact of biologic therapy in persons with Crohn's disease (CD) and ulcerative colitis (UC), we evaluated the effect of marketplace introduction of infliximab on the population rates of hospitalisations and surgeries and public payer drug costs.

Design We used health administrative data to study adult persons with CD and UC living in Ontario, Canada between 1995 and 2012. We used an interrupted time series design with segmented regression analysis to evaluate the impact of infliximab introduction on the rates of IBD-related hospitalisations, intestinal resections and public payer drug costs over 10 years among patients with $C D$ and 5 years among patients with $U C$, allowing for a 1-year transition.

Results Relative to what would have been expected in the absence of infliximab, marketplace introduction of infliximab did not produce significant declines in the rates of CD-related hospitalisations (OR at the last observation quarter $1.06,95 \% \mathrm{Cl} 0.811$ to 1.39 ) or intestinal resections (OR $1.10,95 \% \mathrm{CI} 0.810$ to 1.50$)$, or in the rates of UC-related hospitalisations (OR 1.22, $95 \% \mathrm{Cl} 1.07$ to 1.39 ) or colectomies (OR $0.933,95 \% \mathrm{Cl}$ 0.54 to 1.61). The findings were similar among infliximab users, except that hospitalisation rates declined substantially among UC patients following marketplace introduction of infliximab (OR $0.515,95 \% \mathrm{Cl} 0.342$ to 0.777). There was a threefold rise over expected trends in public payer drug cost among patients with CD following infliximab introduction (OR 2.98,95\% Cl 2.29 to 3.86), suggesting robust market penetration in this group, but no significant change among patients with UC (OR 1.06, $95 \% \mathrm{Cl} 0.955$ to 1.18$)$.

Conclusions Marketplace introduction of infliximab has not yielded anticipated reductions in the population rates of IBD-related hospitalisations or intestinal resections, despite robust market penetration among patients with CD. Misguided use of infliximab in CD patients and underuse of infliximab in UC patients may largely explain our study findings.

\section{BACKGROUND}

Antitumour necrosis factor- $\alpha$ (TNF) antibody therapy has dramatically changed the therapeutic landscape in IBD. Multiple randomised controlled trials (RCTs) have shown this therapy to be efficacious for inducing and maintaining symptomatic remission ${ }^{1-8}$ and reducing the risks of hospitalisations and intestinal resections ${ }^{9-11}$ among patients with moderate-to-severe Crohn's disease (CD) and UC. A meta-analysis of 9 RCTs and 18 observational studies confirmed that infliximab, the first anti-TNF agent introduced for the treatment of IBD, can reduce the risk of hospitalisations and surgeries in patients with IBD. ${ }^{12}$

Anti-TNF and other biologic therapies are costly in comparison to conventional therapies for IBD. In a population-based study from Manitoba, median healthcare costs among anti-TNF users rose dramatically from $\$ 4698 \mathrm{CAD}$ in patients with CD and \$6364CAD in patients with UC in the year prior to anti-TNF therapy, to $\$ 39749 \mathrm{CAD}$ and $\$ 49$ 327CAD, respectively, in the year following anti-TNF initiation. ${ }^{13}$ Over the past decade, these drugs have markedly increased the costs of IBD care and have driven prescription pharmaceuticals to become the single greatest healthcare expenditure among patients with IBD. ${ }^{14-17}$ In Canada, anti-TNF agents account for highest proportion (8.7\%) of public drug programme spending. ${ }^{18}$ While biosimilar agents may reduce the cost of anti-TNF therapy over time, increasing market penetration of biologic and other targeted therapies and a rising worldwide prevalence of IBD $^{19}$ will likely continue to drive up drug costs in coming years. ${ }^{20}$

The extent to which biologic agents offset these costs by reducing the costly and burdensome outcomes of hospitalisations and surgeries among patients with IBD in the real-world remains unknown. In clinical practice, there is likely much greater variability in patient selection, treatment application and patient monitoring than in RCTs, which may significantly reduce treatment effectiveness at a population-level. To optimally impact health outcomes, these agents should be targeted to appropriate patients at the right time in the disease course and therapy should be optimised based on patient response. While it is unlikely that the direct costs savings realised from reductions in hospitalisations and surgeries could ever truly offset the costs 
Significance of this study

What is already known on this subject?

- Randomised controlled trials have demonstrated efficacy of anti-tumour necrosis factor- $\alpha$ antibody (anti-TNF) therapy for moderate-to-severe IBD, including reductions in hospitalisations and surgeries

- Studies of the real-world effects of anti-TNF therapy in patients with IBD are limited.

\section{What are the new findings?}

- In a large geographic population of patients with IBD living in a single public payer healthcare system, marketplace introduction of infliximab did not reduce population rates of IBD-related hospitalisations or intestinal resections among patients with Crohn's disease (CD) or ulcerative colitis (UC).

- Similarly, there were no reductions in hospitalisation or intestinal rates among infliximab users with $C D$, or in colectomy rates among infliximab users with $\mathrm{UC}$, following the introduction of infliximab to the marketplace. However, there were significant declines in hospitalisation rates among infliximab users with UC.

- Market penetration of infliximab has been robust among patients with CD but limited among patients with UC.

\section{How might it impact on clinical practice in the foreseeable} future?

- These findings highlight the challenges with achieving maximal benefit of a proven biologic therapy in a real-world setting.

- Misguided use of anti-TNF therapy among CD patients, and possibly underuse of this theraypy among UC patients, may largely explain our study findings.

- Investigation into the specific reasons for this failing are warranted to develop educational and policy initiatives directed at improving the effectiveness and value of this therapy across the IBD population.

of biologic therapies, an observed reduction in patient morbidity could help justify the increasing use of these agents to policy makers and payers.

We used an interrupted time series (ITS) design to explore the impact of introduction of infliximab into the Canadian marketplace on trends in the rates of IBD-related hospitalisations and surgeries and public payer prescription drug costs in the CD and UC populations of Ontario. The absence of major competing interventions during the period of infliximab introduction, the presence of a single public payer system that provides universal healthcare coverage to Ontario residents and access to routinely collected population-level data facilitated the conduct of our study.

\section{METHODS}

\section{Study setting and data sources}

We conducted a population-based study in adult patients with IBD (aged >18 years) residing in Ontario between 1 July 1995 and 31 March 2012 using provincial health administrative data. Ontario is a geographically and ethnically diverse province of Canada comprising more than 13500000 residents and close to 100000 individuals with IBD. The Ontario government covers $100 \%$ of the costs of medically necessary healthcare services for all its citizens, including hospital-based care, ambulatory physician visits and procedures and chronic care services. It also subsidises the cost of select prescription drugs for individuals aged 65 years or older and those requiring social assistance, through the Ontario Drug Benefits (ODB) Programme, as well as the costs of expensive drugs, such as biologic therapies, on a case-bycase basis through the ODB Exceptional Access Programme. ${ }^{21}$ Across Canada, $41.8 \%$ of prescribed drug spending is paid for by provincial healthcare plans. ${ }^{18}$

Detailed information relating to publicly funded healthcare services is collected by the federal and provincial governments in Canada and constitute routinely collected data. This includes comprehensive data on healthcare utilisation as well as select clinical, sociodemographic and health services data relating to healthcare visits. In Ontario, these data are housed at the Institute for Clinical Evaluative Sciences (ICES) and made available to researchers. ${ }^{22}$ ICES is an independent, non-profit research institute whose legal status under Ontario's health information privacy law allows it to collect and analyse healthcare and demographic data, without consent, for health system evaluation and improvement. In the present study, Ontario datasets were linked using unique encoded identifiers and analysed at ICES. The use of data in this project was authorised under section 45 of Ontario's Personal Health Information Protection Act, which does not require review by a Research Ethics Board. A detailed list of administrative datasets and codes used in this study are provided in online supplementary tables 1 and 2 .

We identified patients with IBD from the Ontario Crohn's and Colitis Cohort, an ICES-derived database of patients with IBD living in Ontario that was created using validated algorithms of IBD-related healthcare contacts. ${ }^{23}{ }^{24}$ We identified hospitalisations and surgeries from the Ontario version of the Canadian Institute for Health Information (CIHI) Discharge Abstract Database, a detailed database of all acute care hospitalisations in Ontario. ${ }^{25}$

\section{Study design}

We used an interrupted time series design with segmented regression analysis to study trends in the aggregate quarterly rates of IBDrelated hospitalisations and intestinal resections and quarterly mean public payer prescription drug costs before and after the date of Health Canada approval of infliximab for CD (6 June 2001) and UC (10 March 2006). ${ }^{26}$ In this approach, observed trends in the rates of health events and costs following marketplace introduction of infliximab (the 'interruption') are compared with trends that would have been expected in the absence of infliximab introduction (the counterfactual), which, in turn, are derived by modelling preinterruption trends and projecting them forward in time. To account for approximately a 1-year lag for infliximab to be listed on the Ontario drug formulary, we excluded the 12-month period following infliximab approval in all ITS analyses. This allowed for post-interruption trends to better coincide with drug penetration into the marketplace.

We used 6years of data to model preinfliximab trends. We terminated the study observation on 31 March 2012, allowing for a 10-year postinfliximab observation period among patients with $\mathrm{CD}$ and a 5-year postinfliximab observation period among patients with UC, following a 1-year transition period. As the validated IBD case ascertainment definition required a 4-year observation window, we limited the postinfliximab observation period to 2012, to allow complete ascertainment of cases by 2016 .

\section{Subgroup analyses}

We conducted subgroup analyses of the effect of marketplace introduction of infliximab in patients with IBD who did and did 
Table 1 Baseline characteristics of study patients on date of nearest quarter following marketplace introduction of infliximab

\begin{tabular}{|c|c|c|c|c|}
\hline & \multicolumn{2}{|c|}{$\begin{array}{l}\text { Crohn's disease } \\
\text { (on } 1 \text { July 2001) }\end{array}$} & \multicolumn{2}{|c|}{$\begin{array}{l}\text { UC } \\
\text { (on } 1 \text { April 2006) }\end{array}$} \\
\hline & $\begin{array}{l}\text { Al patients } \\
\mathrm{n}=21561\end{array}$ & $\begin{array}{l}\text { Publicly } \\
\text { funded } \\
\text { infliximab } \\
\text { users } \\
n=1743\end{array}$ & $\begin{array}{l}\text { All patients } \\
\mathrm{n}=27602\end{array}$ & $\begin{array}{l}\text { Publicly } \\
\text { funded } \\
\text { infliximab } \\
\text { users } \\
\mathrm{n}=585\end{array}$ \\
\hline Age—-median (IQR) & $41(32-53)$ & $36(27-47)$ & $48(38-61)$ & $42(28-57)$ \\
\hline \multicolumn{5}{|l|}{ Sex } \\
\hline$\%$ Male & 43.4 & 46.5 & 50.3 & 56.9 \\
\hline$\%$ Female & 56.6 & 53.5 & 49.7 & 43.1 \\
\hline \multicolumn{5}{|l|}{ Income quintile } \\
\hline$\%$ Q1 & 16.8 & 20.6 & 15.5 & 16.8 \\
\hline \% Q2 & 19.9 & 20.6 & 18.5 & 20.0 \\
\hline$\%$ Q3 & 20.5 & 20.5 & 20.3 & 20.0 \\
\hline$\%$ Q4 & 20.4 & 18.0 & 21.9 & 20.7 \\
\hline \% Q4 & 22.0 & 19.3 & 23.4 & 21.4 \\
\hline Unknown & 0.5 & 1.1 & 0.4 & 1.2 \\
\hline \multicolumn{5}{|l|}{ Residential setting } \\
\hline$\%$ Rural & 13.2 & 15.3 & 12.4 & 11.6 \\
\hline$\%$ Urban & 86.4 & 83.6 & 87.3 & 87.5 \\
\hline \% Unknown & 0.3 & 1.0 & 0.2 & 0.9 \\
\hline
\end{tabular}

not receive publicly funded infliximab during the study period, as recorded in the ODB database. We estimated that publicly funded infliximab users would reflect approximately $40 \%$ of all infliximab users in the IBD population (the remainder would have received funding through private drug plans) and comprise a greater proportion of individuals aged 65 years or older (who automatically qualify for ODB coverage) and of those with severe or medically refractory disease as compared with the general IBD population. Many non-elderly patients with IBD without private drug plans would have also qualified for government assistance through the Ontario Drug Benefits Exceptional Access Programme and been captured in this subgroup. ${ }^{21}$ Individuals not receiving publicly funded infliximab could have received infliximab through private funding, but these patients would comprise a small minority of the remaining population. We maintained the same study design for these subgroup analyses.

\section{Outcome definitions}

We defined an IBD-related hospitalisation based on the presence of an International Classification of Diseases (ICD), Ninth Revision (ICD-9) (before 1 April 2002) or ICD-10 (1 April 2002 onwards) hospital discharge diagnosis of either $\mathrm{CD}$ or $\mathrm{UC}$ as the most responsible comorbid, or primary interservice or interhospital transfer diagnosis, as defined by CIHI. ${ }^{25}$ We defined intestinal resection as either a small or large bowel resection among patients with $\mathrm{CD}$ and a large bowel resection among patients with UC, using a validated list of Canadian Classification of Interventions codes, ${ }^{27} 28$ which were adapted to Canadian Classification of Procedures codes for surgeries occurring before 1 April 2002 (online supplementary table 2).

\section{Analytic methods}

We tabulated quarterly event rates and costs between 1 July 1995 and 31 March 2012 for all persons with CD and between 1 April 2000 and 31 March 2012 for all persons with UC. Only persons with established $\mathrm{CD}$ or $\mathrm{UC}$ at the start of a quarter and valid Ontario healthcare registration throughout a quarter were eligible for analysis in that quarter. Only the first relevant hospitalisation or surgery within a quarter was considered for each person. A hospitalisation that carried over between quarters was assigned to the quarter in which a patient was initially admitted to hospital.

We conducted linear segmented regression analysis of the quarterly data to test for any statistically significant changes in event rates and costs from the preinfliximab period to the postinfliximab period. The preinfliximab period consisted of 24 data points for the analyses of hospitalisation and surgery rates and 12 data points for the analyses of publicly funded drug costs. The four quarters immediately following infliximab regulatory approval were designated as a transition period until formulary listing and were excluded from the analysis.

Quarterly hospitalisation and surgery rates were logittransformed while cost data were log transformed prior to analysis to improve normality and to allow the models to obey asymptotic trends. Model parameters were estimated using maximum likelihood. These included coefficients representing the intercept and slope prior to infliximab approval, as well as changes in intercept and slope following infliximab approval. To account for possible autocorrelation in the time series data, we introduced first-order, second-order, third-order and fourthorder autoregressive terms in all models. We used automated backwards elimination to eliminate autocorrelation terms that were not statistically significant.

Regression coefficients from the analysis (preinterruption intercept and slope and postinterruption intercept and slope changes) were exponentiated and expressed for hospitalisation and surgery rates using ORs and for mean costs using relative change, together with $95 \%$ CIs. We used the regression coefficients from the preinfliximab period to model the counterfactual. We summarised the overall effect of marketplace introduction of infliximab by calculating the difference between the modelbased rates following marketplace infliximab introduction and the counterfactual rate at the last observation quarter. We backtransformed predicted event rates and costs from the model to plot the modelled trendlines, superimposed on the observed data. We examined goodness of fit by inspecting residual plots and comparing the observed data to the predicted trends from the model. All analyses were conducted using SAS V.9.4 (SAS Institute, Cary, North Carolina, USA).

\section{RESULTS \\ Study patients}

The number of individuals contributing quarterly data to our primary analyses gradually increased from 13603 (quarter 3 (Q3), 1995) to 35904 (Q1, 2012) for CD and from 18894 (Q2, 2000) to $37210(\mathrm{Q} 1,2012)$ for UC. Among publicly funded infliximab users, the respective numbers of individuals rose from 948 to 3654 for CD and from 232 to 1223 for UC. As of the last observation quarter, $10.2 \%$ of persons with $\mathrm{CD}$ and $3.3 \%$ of persons with UC had received infliximab through public assistance.

Among patients with $\mathrm{CD}$, the median age increased from 37 (IQR 29-49) to 47 (IQR 36-58) years for the overall population and from 33 (IQR 26-44) to 39 (IQR 28-52) years for publicly funded infliximab users over the study period. Among patients with $\mathrm{UC}$, the median age increased from 45 (IQR 35-59) to 51 (IQR 40-63) years for the overall population and from 42 (IQR 32-53) to 42 (IQR 28-59) years for publicly funded infliximab users. The distribution of sex, income quintile and residential location (rural vs urban) remained relatively stable over time in the overall $\mathrm{CD}$ and UC populations (online supplementary tables 3 and 4).

Compared with all persons with IBD in the population, publicly funded infliximab users were generally younger, 


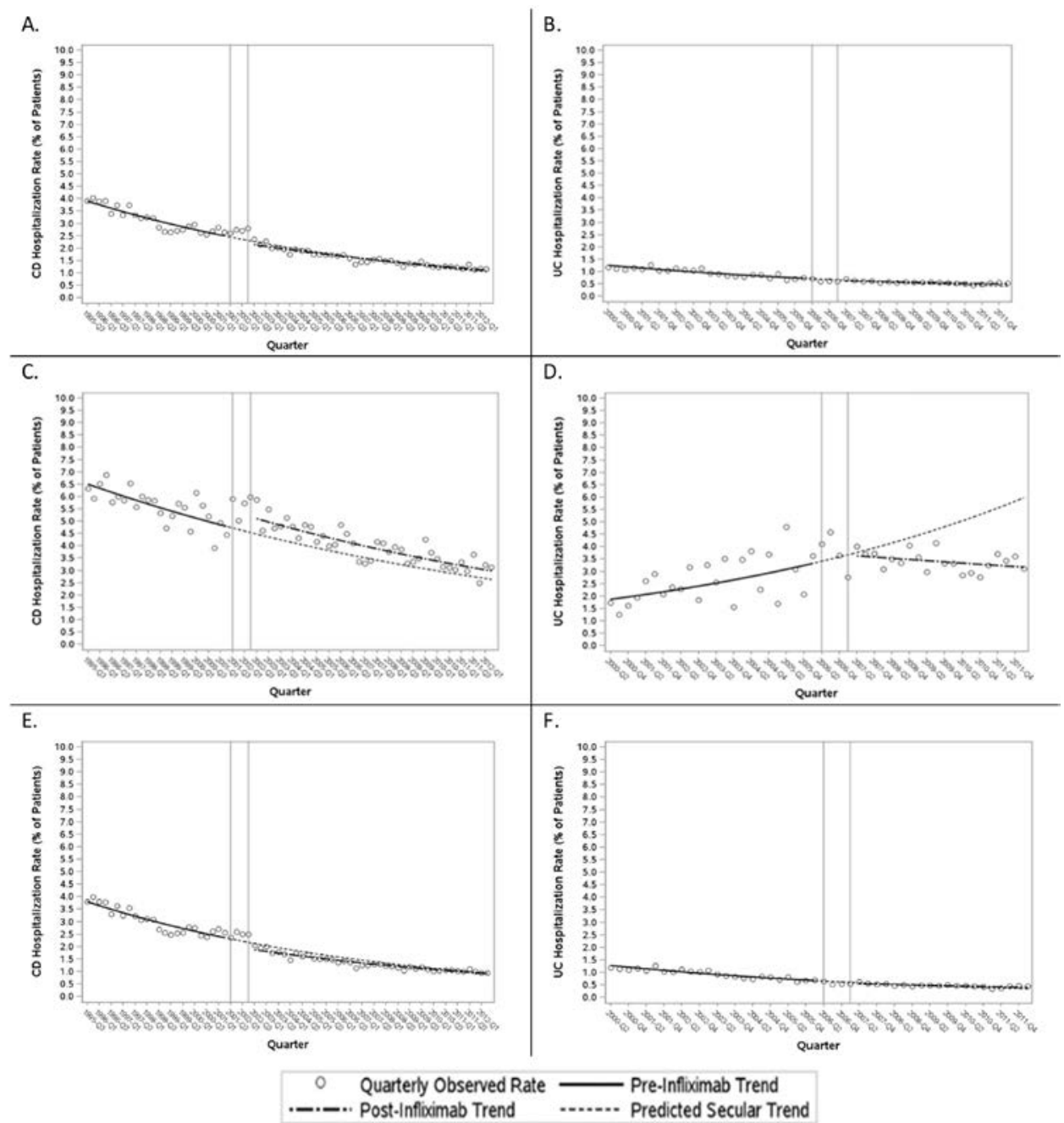

Figure 1 Observed and secular trends for rates of IBD-related hospitalisations in Ontario, based on interrupted time series analysis with segmented regression. (A) All patients with Crohn's disease (CD); (B) all patients with UC; (C) patients with CD receiving publicly funded infliximab; (D) patients with UC receiving publicly funded infliximab; (E) patients with CD not receiving publicly funded infliximab; (F) patients with UC not receiving publicly funded infliximab.

comprised a higher proportion of males, had marginally lower household income and were slightly more likely to be living in a rural location (table 1).

\section{Trends in hospitalisation rates}

Patients with $C D$, overall cohort (primary analysis)

Prior to infliximab introduction, there was a gradual $2 \%$ decline per quarter in the odds of IBD-related hospitalisation among persons with CD (quarterly OR $0.980,95 \%$ CI 0.975 to 0.985 ). This rate of decline did not change after infliximab introduction (change in slope OR 1.00, 95\% CI 0.998 to 1.01). Overall, by the last quarter, marketplace introduction of infliximab was not associated with a significant decline in $\mathrm{CD}$-related hospitalisation rates (OR for observed vs counterfactual difference $1.06,95 \%$ CI 0.811 to 1.39 ) (figure 1A, online supplementary table 5).

Patients with $C D$, subgroup analyses of patients who did or did not receive publicly funded infliximab

Across subgroups of patients with CD who did or did not receive publicly funded infliximab, the decline in hospitalisation rates prior to marketplace infliximab introduction was similar to that in the overall cohort and there was no significant change in this rate of decline following infliximab introduction. While there was a statistically significant increase in the intercept immediately following marketplace infliximab introduction in the subgroup of patients who received publicly funded infliximab, and a reciprocal decrease in the intercept in the subgroup of patients who did not receive publicly funded infliximab, the combined effect at the last observation quarter was not statistically significant in either subgroup (observed vs counterfactual OR 1.13, 95\% CI 0.885 to 1.45 , for those receiving publicly funded infliximab and OR $0.979,95 \%$ CI 0.723 to 1.33 , for those not receiving publicly funded infliximab) (figure $1 \mathrm{C}$ and $\mathrm{E}$, online supplementary table 5).

Patients with UC, overall cohort (primary analysis)

Prior to infliximab introduction, there was a $2.4 \%$ quarterly decline in the odds of IBD-related hospitalisation among persons with UC (quarterly OR $0.976,95 \%$ CI 0.973 to 0.979 ). This rate of decline was attenuated slightly following introduction of infliximab, such that, by the last observation quarter, marketplace introduction of infliximab was associated with a statistically significant higher rate of UC-related hospitalisation (observed vs counterfactual OR 1.22, 95\% CI 1.07 to 1.39 ) (figure $1 \mathrm{~B}$, online supplementary table 6). 
Patients with UC, subgroup analyses of patients who did or did not receive publicly funded infliximab

In contrast to the overall cohort, in the small subgroup of patients with UC who received publicly funded infliximab, the quarterly rate of IBD-related hospitalisations was rising prior to marketplace introduction of infliximab (quarterly OR 1.03, 95\% CI 1.02 to 1.04). Following the interruption, hospitalisation rates began to decline quarter over quarter, such that, by the last observation quarter, marketplace infliximab introduction was associated with a markedly lower IBD-related hospitalisation rate as compared with what would have been expected in the absence of its introduction (observed vs counterfactual OR $0.515,95 \%$ CI 0.342 to 0.777 ) (figure $1 \mathrm{D}$, online supplementary table 6). Trends among patients who did not receive publicly funded infliximab mirrored those of the overall cohort prior to marketplace infliximab introduction (OR 0.972 , 95\% CI 0.969 to 0.976 ), whereas there was a slight increase in IBD-related hospitalisation rates over what would have been otherwise expected by the last observation quarter (observed vs counterfactual OR $1.18,95 \%$ CI 1.03 to 1.35 ) (figure $1 \mathrm{~F}$, online supplementary table 6).

\section{Trends in intestinal resection rates}

Patients with $C D$, overall cohort (primary analysis)

Prior to marketplace introduction of infliximab, there was a gradual $1.6 \%$ quarterly decline in the odds of intestinal resection among persons with CD (quarterly OR $0.984,95 \%$ CI 0.979 to 0.99). This rate of decline did not change significantly following the interruption, such that, by the last quarter, marketplace infliximab introduction was not associated with a statistically significant effect on intestinal resection rates (observed vs counterfactual OR $1.10,95 \% \mathrm{CI} 0.810$ to 1.50 ) (figure $2 \mathrm{~A}$, online supplementary table 7).

Patients with $C D$, subgroup analyses of patients who did or did not receive publicly funded infliximab

Across subgroups of patients with CD who did or did not receive publicly funded infliximab, there was a steady decline in intestinal rates prior to marketplace infliximab introduction, although this decline was less pronounced among infliximab users (figure $2 \mathrm{C}$ and $\mathrm{E}$, online supplementary table 7 ). Similar to the overall cohort, there was no statistically significant effect
A.
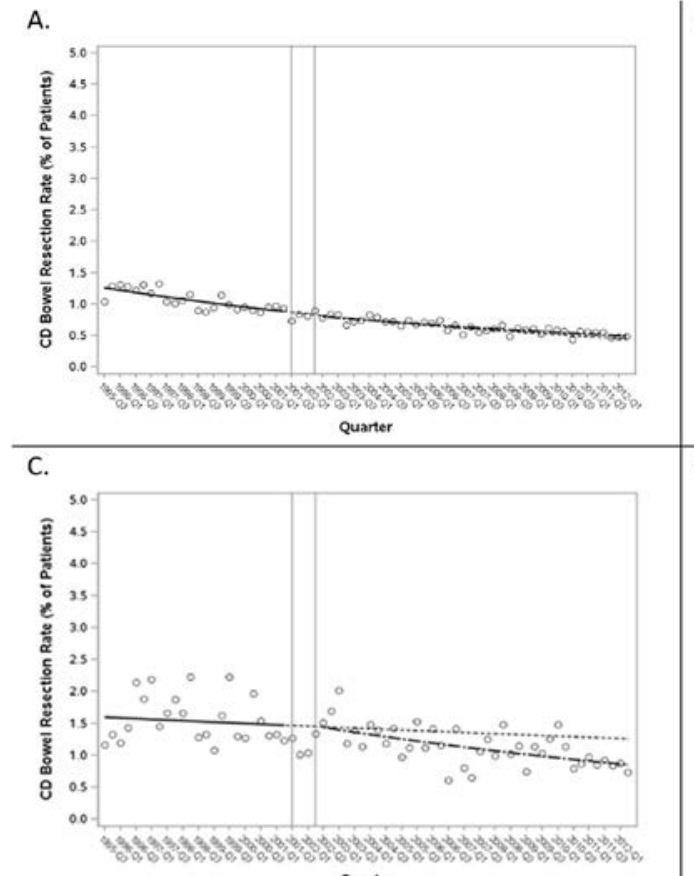

E.

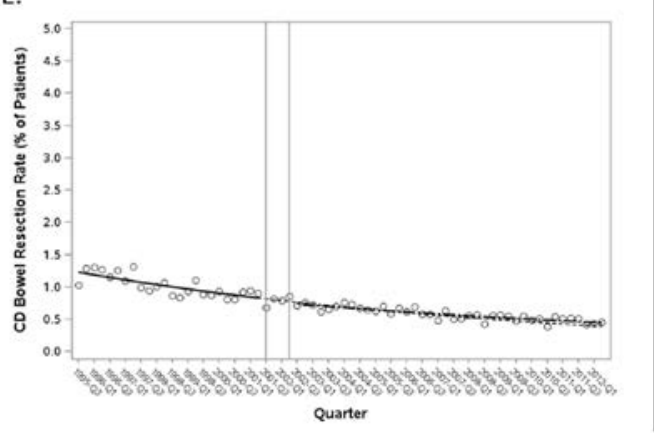

F.

B.

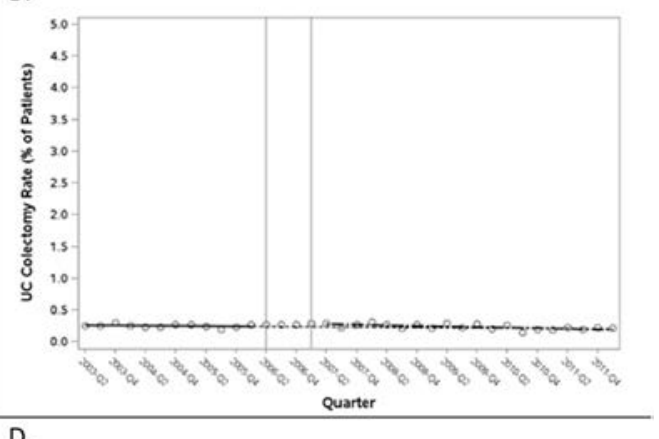

D.
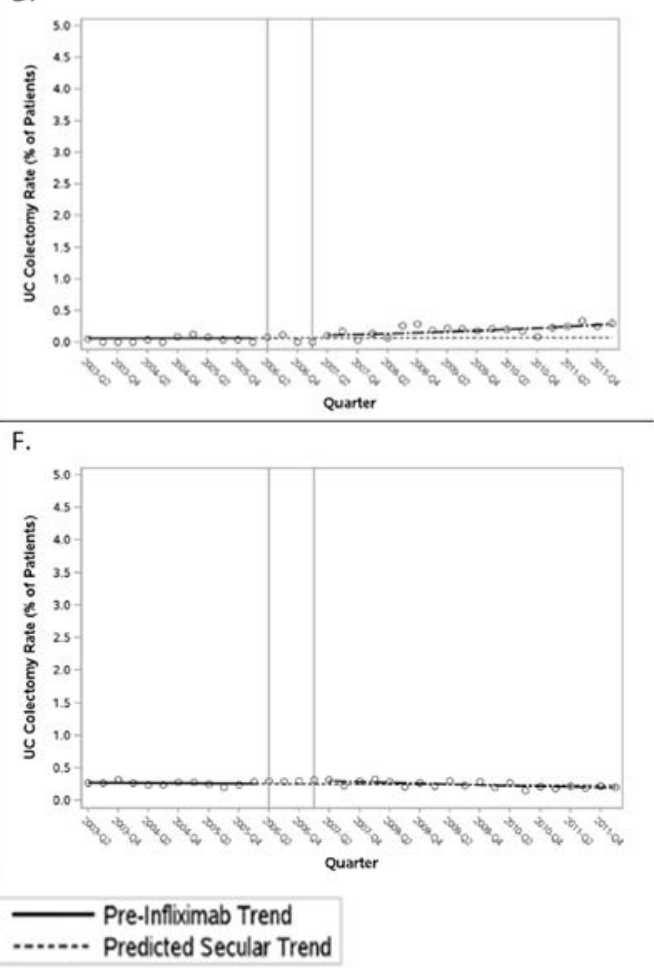

Figure 2 Observed and secular trends for rates of intestinal resections among patients with IBD in Ontario, based on interrupted time series analysis with segmented regression. (A) All patients with $C D ;(B)$ all patients with UC; (C) patients with CD receiving publicly funded infliximab; (D) patients with UC receiving publicly funded infliximab; $(E)$ patients with $C D$ not receiving publicly funded infliximab; (F) patients with UC not receiving publicly funded infliximab. 
of infliximab introduction on intestinal resection rates in either subgroup (observed vs counterfactual OR 0.672, 95\% CI 0.315 to 1.43 , for those receiving publicly funded infliximab and OR $1.14,95 \%$ CI 0.820 to 1.58 , for those not receiving publicly funded infliximab), although there was a numerical and visual decline in slope among infliximab users (figure $2 \mathrm{C}$ and $\mathrm{E}$, online supplementary table 8).

Patients with UC, overall cohort (primary analysis)

Prior to infliximab introduction, there was a negligible decline in the quarterly odds of colectomy among patients with UC (quarterly OR $0.993,95 \%$ CI 0.975 to 1.01 ). This rate of decline did not change significantly after marketplace introduction of infliximab, such that, by the last quarter, marketplace introduction of infliximab was not associated with a significant reduction in the colectomy rate (observed vs counterfactual OR 0.933, 95\% CI 0.540 to 1.61 ) (figure $2 \mathrm{~B}$, online supplementary table 8 ).

Patients with UC, subgroup analyses of patients who did or did not receive publicly funded infliximab

Across subgroups of patients with UC who did or did note receive publicly funded infliximab, there was no statistically significant effect of infliximab introduction on the colectomy rate by the last quarter of observation (observed vs counterfactual OR $4.17,95 \%$ CI 0.145 to 119 , for those receiving publicly funded infliximab and OR $0.841,95 \%$ CI 0.487 to 1.45 , for those not receiving publicly funded infliximab) (figure $2 \mathrm{D}$ and $\mathrm{F}$, online supplementary table 8 ). Notably, low absolute event rates resulted in wide CIs in these analyses.

\section{Trends in public payer prescription drug costs}

Patients with $C D$

Among patients with $\mathrm{CD}$, there was a marked rise in the mean public payer prescription drug cost over 10 years following marketplace infliximab introduction relative to what would have been expected in the absence of infliximab introduction, including an abrupt rise of 34\% (relative change in intercept $1.34,95 \%$ CI 1.29 to 1.41 ) and a further $2 \%$ rise per quarter (relative change in slope $1.02,95 \%$ CI 1.01 to 1.02 ). By the final quarter, the combined effect was a near threefold rise in mean public payer prescription drug costs over what would have been expected had infliximab not been introduced (observed vs counterfactual relative difference 2.98 , 95\% CI 2.29 to 3.86) (figure $3 \mathrm{~A}$, online supplementary table 9). The rise in

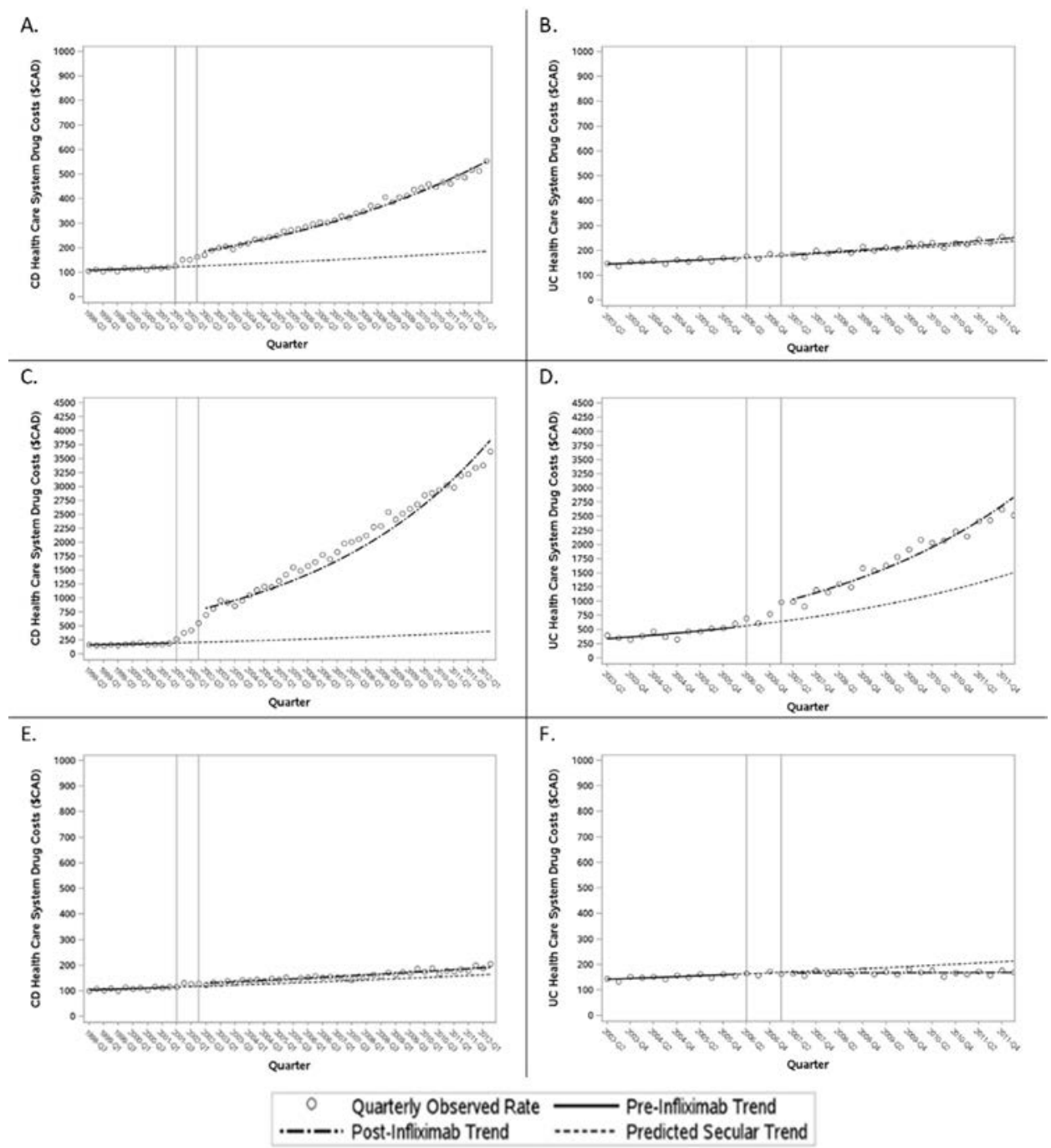

Figure 3 Observed and secular trends for public payer prescription drug costs in Ontario, based on ITS analysis with segmented regression. (A) All patients with $C D ;(B)$ all patients with UC; (C) patients with CD receiving publicly funded infliximab; (D) patients with UC receiving publicly funded infliximab; (E) patients with CD not receiving publicly funded infliximab; $(F)$ patients with UC not receiving publicly funded infliximab. 
public payer prescription drug cost was close to 10 -fold greater than expected by the last observation quarter in the subgroup of patients with $\mathrm{CD}$ who received publicly funded infliximab (observed vs counterfactual relative change 9.49, 95\% CI 4.45 to 20.3) (figure 3C, online supplementary table 9). Conversely, there was no change in public payer prescription drug cost in the subgroup of patients with CD who did not receive publicly funded infliximab (observed vs counterfactual relative change $1.17,95 \% \mathrm{CI} 0.875$ to 1.57 ) (figure $3 \mathrm{E}$, online supplementary table 9), confirming the that the rise in public payer drug costs in the overall cohort following marketplace infliximab introduction was due to infliximab use.

\section{Patients with UC}

Among patients with UC, conversely, there was no statistically significant effect of marketplace introduction of infliximab on the public payer prescription drug cost over 5 years relative to what would have been expected in the absence of infliximab introduction (observed vs counterfactual relative difference in last observation quarter $1.06,95 \% \mathrm{CI} 0.955$ to 1.18 ) (figure $3 \mathrm{~B}$, online supplementary table 7 ). There was a near twofold increase in the public payer prescription drug cost by the last observation quarter over what would have been otherwise expected in the subgroup of patients with UC who received publicly funded infliximab (observed vs counterfactual relative change 1.88, $95 \%$ CI 1.14 to 3.12), and a reciprocal decrease in the public payer prescription drug cost in the subgroup of patients with UC who did not receive publicly funded infliximab (observed vs counterfactual relative change $0.790,95 \% \mathrm{CI} 0.704$ to 0.886 ) (figure 3D and F, online supplementary table 10 ).

\section{DISCUSSION}

In our analysis of a large geographic population of patients with IBD, marketplace introduction of infliximab did not result in statistically significant reductions in the rates of IBD-related hospitalisations or intestinal resections in patients with $\mathrm{CD}$ over 10 years or in patients with UC over 5 years, over and above what would have been expected to occur in the absence of infliximab introduction (ie, if the pre-existing secular trends had continued unaltered). Even among patients with $\mathrm{CD}$ who received publicly funded infliximab, there was no change in trend in the rates of IBD-related hospitalisations or intestinal resections. However, patients with UC who received publicly funded infliximab showed a marked reduction in the rate of IBD-related hospitalisations following marketplace infliximab introduction, which was not observed among patients with UC who did not receive publicly funded infliximab.

There was a three-fold rise in public payer prescription drug costs over expected trends among patients with CD over 10 years following marketplace infliximab introduction, but no change over expected trends among patients with UC over 5 years. There was a near 10-fold rise in public payer drug costs among patients with $\mathrm{CD}$ who received publicly funded infliximab, whereas there was no change among patients with $\mathrm{CD}$ who did not receive publicly funded infliximab, confirming that the overall rise in drug costs in this population was due to infliximab use. There was a less pronounced two-fold rise public payer drug costs among patients with UC who received publicly funded infliximab, which was offset in the overall UC population by a decrease public payer drug costs among patients who did not receive publicly funded infliximab. Overall, these findings support that there was significant market penetration of infliximab among patients with $C D$ in Ontario but limited penetration among patients with UC during the study period. Publicly funded infliximab users accounted for
$10.2 \%$ of the CD population and $3.3 \%$ of the UC population by the end of the respective observation periods. We estimate that this represents roughly $40 \%$ of all infliximab users with IBD, based on the proportion of nationwide drug spending contributed by the public payer. ${ }^{21}$ By this estimate, close to $25 \%$ of patients with $\mathrm{CD}$ would have received infliximab (through public or private funding) over the 10 -year observation period, while just $8 \%$ of patients with UC would have received infliximab over a 5-year observation period.

Taken collectively, our findings suggest that increasing infliximab usage has not resulted in meaningful declines in diseaserelated hospitalisation or intestinal resection rates among patients with CD. Conversely, limited infliximab usage among patients with UC may have stifled any potential for declines in event rates at a population level, which were otherwise observed in the small subgroup of infliximab users. Importantly, individuals who received publicly funded infliximab may have differed in important disease characteristics from the general IBD population, including having greater representation of elderly individuals (as all persons aged 65 years or older, but not all persons under age 65 , qualify for public drug funding) as well as individuals with aggressive and/or treatment-refractory disease, particularly those in younger age groups (as evidenced by the lower median age among publicly funded infliximab users in this study); therefore, caution should be exercised when comparing trends in this subgroup with those of the broader IBD population.

The findings in the CD population are surprising, as infliximab has proven itself to be an excellent drug for the treatment of CD in RCTs ${ }^{1929}$ and the only biologic agent that has been shown in a dedicated RCT to heal perianal fistulas. ${ }^{3}$ Real-world experience has substantiated the clinical trial experience that infliximab is an effective therapy for improving symptoms and inducing mucosal healing in $\mathrm{CD}$. We hypothesise that misguided use and failure to optimise infliximab in many patients with $C D$, as well as underuse of this agent among patients with UC, may largely explain the underperformance of this treatment in the clinical practice setting.

While UC remains predominantly an inflammatory disease throughout its course, up to $50 \%$ of patients with CD develop symptomatic strictures and fistulas, ${ }^{30} 31$ which often do not respond to immunosuppressive treatment and require surgery. Misdirected use of infliximab for these indications alongside insufficient use in persons with moderate-to-severe inflammatory CD early in the disease course, prior to the development of such complications, could have attenuated a potential benefit of infliximab in this population. Strategies that are now recognised to optimise infliximab efficacy were also likely underused during the study period, including use of concomitant immunosuppressive therapy with a thiopurine or methotrexate, ${ }^{29}{ }^{32-34}$ use of accelerated step-up treatment ${ }^{35}$ and therapeutic drug monitoring ${ }^{36}$ to optimise therapeutic potential, and application of a treat-to-target strategy based on objective measures. ${ }^{37} 38$ As methods of applying anti-TNF and other biologic therapies in patients with IBD improve, the merits of this treatment may become more apparent at a population level.

Importantly, our analysis evaluated the impact of infliximab in the context of all other treatments available for IBD patient care, whereas large RCTs of infliximab did not compare this agent to best available care..$^{1-3}$ The fact that hospitalisation and surgery rates were already declining prior to marketplace introduction of infliximab suggests that non-biologic interventions alone could temper the need for biologic therapies. Finally, it is possible that infliximab and other biologics simply have a limited 
capacity to influence hospitalisation and surgery rates outside of the clinical trial setting.

While several population-based studies have evaluated temporal trends in colectomy rates among patients with UC, ${ }^{39-41}$ none has used a rigorous approach to assess the impact of infliximab on observed trends. A major strength of using ITS design with segmented regression is that it evaluates trends in the entire at-risk IBD population while controlling for underlying secular trends. ${ }^{42-44}$ While ITS design does not assess individual-level effects, a traditional cohort design comparing infliximab users to non-users would be fraught with selection and treatment biases, as infliximab is typically administered to the sickest and most medically refractory patients with IBD. Even rigorous multivariable analysis and propensity score matching would be unable to control for many important confounders in such a design.

Potential threats to the internal validity of ITS design are co-interventions or changes in data collection coinciding with the timing of the intervention under study, which could confound the relationship between the primary intervention and outcome rates. We are confident that there were no major competing treatments, paradigm changes in IBD patient care or healthcare system reforms in Ontario coinciding with marketplace introduction of infliximab. Although adalimumab (another anti-TNF agent) was introduced for CD in 2007, we did not expect this to have a major impact on the interpretability of our findings as it has a very similar mechanism of action as infliximab. Importantly, ongoing systemic improvements to IBD patient care would have been integrated into the modelled secular trends, against which the postintervention trends were compared, and thus do not represent a major threat to the validity or interpretability of results in ITS design. Furthermore, we are reassured in the precision of the pre-infliximab regression lines, which were used to project post-infliximab trends, due to the close scatter of data points around the modelled trendlines, particularly in our analyses of the overall IBD populations.

A limitation of our study was that we could only study publicly funded infliximab users in our subgroup analysis. This group likely comprises greater proportions of elderly and marginalised individuals as well as individuals with more treatment-refractory disease (as public funding for biologics requires documented failure of conventional immunosuppressive therapy) relative to the broader population of infliximab users. Future studies that evaluate outcomes among all infliximab users at a population level would be useful to validate the findings of our subgroup analysis.

Another limitation is the absence of detailed clinical data to identify potential causative factors for the absence of declines in hospitalisation and intestinal resection rates following infliximab introduction, particularly among patients with CD. Future studies using rigorous data collection methods will be required to address this in order to develop targeted education and policy initiatives aimed at realising the full benefits of this therapy.

We were also unable to account for off-label infliximab use or its use as part of a clinical trial in some patients prior to its regulatory approval for IBD, although we suspect that such usage would have been minimal relative to the usage following regulatory approval.

Finally, as there are unique aspects to healthcare delivery and funding in Ontario, our results may not be generalisable to all IBD populations and require confirmation in studies from other jurisdictions.

While it may be disappointing that marketplace introduction of infliximab has not impacted overall IBD hospitalisation and intestinal resection rates, it is important to consider that this does not capture the full breadth of potential impact of this treatment, which includes its effects on quality of life, functional capacity and workplace productivity. These should be addressed in future prospective studies before concluding that anti-TNF therapy has not impacted the health of patients with IBD at a population level.

In summary, we did not observe an appreciable impact of marketplace introduction of infliximab on the population rates of IBD-related hospitalisations or intestinal resections among patients with CD or UC, despite robust market penetration of this agent in the $\mathrm{CD}$ population. We hypothesise that misguided use and failure to optimise use of infliximab, particularly among patients with $\mathrm{CD}$, as well as possibly underuse of infliximab among patients with UC, contributed substantially to underperformance of this treatment in clinical practice. Future studies should aim to identify causative factors for the absence of decline in major adverse event rates as well as the impact of infliximab and other biologic therapies on IBD patient quality of life and indirect costs. Our findings should also be verified in other jurisdictions to confirm that this is a widespread issue affecting the use of infliximab in patients with IBD. Ultimately, clinicians, policy makers and payers must understand how to optimise use and access of this proven therapy to maximally impact patient morbidity and thereby justify the escalating costs associated with this treatment.

\section{Author affiliations}

${ }^{1}$ Department of Medicine, University of Ottawa, Ottawa, Ontario, Canada

${ }^{2}$ Division of Gastroenterology, The Ottawa Hospital IBD Centre, Ottawa, Ontario,

Canada

${ }^{3}$ Clinical Epidemiology Program, OttawaHospital Research Institute, Ottawa, Ontario,

Canada

${ }^{4}$ School of Epidemiology and Public Health, University of Ottawa, Ottawa, Ontario,

Canada

${ }^{5}$ ICES uOttawa, Ottawa, Ontario, Canada

${ }^{6}$ Children'sHospital of Eastern Ontario (CHEO) Inflammatory Bowel Disease Centre,

Divisionof Gastroenterology, Hepatology and Nutrition, Ottawa, Ontario, Canada

${ }^{7}$ Department of Pediatrics, University of Ottawa, Ottawa, Ontario, Canada

${ }^{8}$ CHEOResearch Institute, Ottawa, Ontario, Canada

${ }^{9}$ Department of Internal Medicine, University of Manitoba, Winnipeg, Manitoba,

Canada

${ }^{10}$ Health Sciences Centre Winnipeg, Winnipeg, Manitoba, Canada

${ }^{11}$ Departments of Medicine and Community Health Sciences, University of Calgary, Calgary, Alberta, Canada

${ }^{12}$ Foothills Medical Centre, Division of Gastroenterology and Hepatology, Calgary, Alberta, Canada

Correction notice This article has been corrected since it published Online First. The disclaimer statement, figure 2 legend and significance of this study box has been updated.

Contributors All coauthors made substantial contributions to study design, data interpretation and critical revision of the manuscript for important intellectual content. SKM was most responsible for all aspects of the study, including drafting and finalising the manuscript and all requested revisions. JB was responsible for data acquisition and statistical programming. MT was responsible for guiding the statistical analysis.

Funding This study was funded by the Department of Medicine, University of Ottawa and the Canadian Institutes of Health Research (Project Grant \# 162393). This study was supported by IC/ES, which is funded by an annual grant from the Ontario Ministry of Health and Long-Term Care (MOHLTC).

Disclaimer The opinions, results and conclusions reported in this paper are those of the authors and are independent from the funding sources. Parts of this paper are based on data and information provided by the Canadian Institute for Health Information (CIHI). No endorsement by ICES, MOHLTC or $\mathrm{CIHI}$ is intended or should be inferred.

Competing interests $\mathrm{COI}$ Statement: SKM has received honoraria for speaking or consultancy from AbbVie, Janssen, Takeda, Pfizer, Shire and Ferring. JB has no conflicts of interest. EIB has no conflicts of interest. CNB has served on advisory boards of AbbVie Canada, Ferring Canada, Janssen Canada, Napo Pharmaceuticals, Pfizer Canada, Shire Canada, Takeda Canada, and has consulted to 4D Pharma and Mylan Pharmaceuticals. He has received unrestricted educational grants from AbbVie Canada, Janssen Canada, Shire Canada and Takeda Canada. He has been on speaker's bureau of Ferring Canada and Shire Canada. GG has received honoraria for speaking or consultancy from AbbVie, Janssen, Pfizer and Takeda, and research support from Janssen, AbbVie, GlaxoSmithKline, Merck and Shire. He shares 
ownership of a patent: Treatment ofInflammatory Disorders, Autoimmune Disease and PBC . UTI Limited Partnership, assignee, Patent 62/555,397, 7 September 2017. JDMcC has received honoraria for speaking or consultancy from AbbVie, Janssen, Takeda, Pfizer, Shire and Ferring. HS has served on advisory boards of Ferring Canada, Takeda Canada, Merck Canada and received research funding from Merck Canada. LT has received research funding from Janssen Canada, and served on advisory boards for AbbVie Canada, Takeda Canada, Merck Canada, Pfizer Canada and Mallinckrodt USA.

\section{Patient consent for publication Not required.}

Provenance and peer review Not commissioned; externally peer reviewed.

Data sharing statement The dataset from this study is held securely in coded form at ICES. While data sharing agreements prohibit ICES from making the dataset publicly available, access may be granted to those who meet prespecified criteria for confidential access, available at http://www.ices.on.ca/DAS. The full dataset creation plan and underlying analytic code are available from the authors on request, understanding that the computer programs may rely on coding templates or macros that are unique to ICES and are therefore either inaccessible or may require modification.

Open access This is an open access article distributed in accordance with the Creative Commons Attribution Non Commercial (CC BY-NC 4.0) license, which permits others to distribute, remix, adapt, build upon this work non-commercially, and license their derivative works on different terms, provided the original work is properly cited, appropriate credit is given, any changes made indicated, and the use is non-commercial. See: http://creativecommons.org/licenses/by-nc/4.0/.

\section{ORCID iDs}

Sanjay K Murthy http://orcid.org/0000-0002-0128-7897

Eric I Benchimol http://orcid.org/0000-0001-8855-3598

Gilaad G Kaplan http://orcid.org/0000-0003-2719-0556

\section{REFERENCES}

1 Hanauer SB, Feagan BG, Lichtenstein GR, et al. Maintenance infliximab for Crohn's disease: the ACCENT I randomised trial. Lancet 2002;359:1541-9.

2 Rutgeerts P, Sandborn WJ, Feagan BG, et al. Infliximab for induction and maintenance therapy for ulcerative colitis. $N$ Engl J Med Overseas Ed 2005;353:2462-76.

3 Sands BE, Anderson FH, Bernstein CN, et al. Infliximab maintenance therapy for fistulizing crohn's disease. N Eng/ J Med Overseas Ed 2004;350:876-85.

4 Sandborn WJ, van Assche G, Reinisch W, et al. Adalimumab induces and maintains clinical remission in patients with moderate-to-severe ulcerative colitis. Gastroenterology 2012;142:257-65.

5 Sandborn WJ, Feagan BG, Marano C, et al. Subcutaneous golimumab induces clinical response and remission in patients with moderate-to-severe ulcerative colitis. Gastroenterology 2014;146:85-95.

6 Sandborn WJ, Feagan BG, Marano C, et al. Subcutaneous golimumab maintains clinical response in patients with moderate-to-severe ulcerative colitis. Gastroenterology 2014;146:96-109.

7 Colombel JF, Sandborn WJ, Rutgeerts P, et al. Adalimumab for maintenance of clinical response and remission in patients with Crohn's disease: the CHARM trial. Gastroenterology 2007;132:52-65.

8 Targan SR, Hanauer SB, van Deventer SJ, et al. A short-term study of chimeric monoclonal antibody CA2 to tumor necrosis factor alpha for Crohn's disease. Crohn's Disease CA2 Study Group. N Engl J Med 1997;337:1029-35.

9 Lichtenstein GR, Yan S, Bala M, et al. Infliximab maintenance treatment reduces hospitalizations, surgeries, and procedures in fistulizing Crohn's disease. Gastroenterology 2005;128:862-9.

10 Sandborn WJ, Rutgeerts P, Feagan BG, et al. Colectomy rate comparison after treatment of ulcerative colitis with placebo or infliximab. Gastroenterology 2009:137:1250-60.

11 Feagan BG, Panaccione R, Sandborn WJ, et al. Effects of adalimumab therapy on incidence of hospitalization and surgery in Crohn's disease: results from the CHARM study. Gastroenterology 2008;135:1493-9.

12 Costa J, Magro F, Caldeira D, et al. Infliximab reduces hospitalizations and surgery interventions in patients with inflammatory bowel disease: a systematic review and meta-analysis. Inflamm Bowel Dis 2013;19:2098-110.

13 Targownik LE, Witt JC, Tennakoon A, et al. Mo1871 - Direct Costs of Care Among Patients with Inflammatory Bowel Disease before and after Initiation of Anti-TNF Therapy. Gastroenterology 2018;154:S-833-833.

14 Kappelman MD, Rifas-Shiman SL, Porter CQ, et al. Direct health care costs of Crohn's disease and ulcerative colitis in US children and adults. Gastroenterology 2008; 135:1907-13.

15 Kuenzig ME, Benchimol El, Lee L, et al. The Impact of Inflammatory Bowel Disease in Canada 2018: Direct Costs and Health Services Utilization. Journal of the Canadian Association of Gastroenterology 2018. gwy055-gwy055.
16 Prenzler A, Bokemeyer B, von der Schulenburg JM, et al. Health care costs and their predictors of inflammatory bowel diseases in Germany. Eur J Health Econ 2011;12:273-83.

17 van der Valk ME, Mangen MJ, Leenders M, et al. Healthcare costs of inflammatory bowel disease have shifted from hospitalisation and surgery towards anti-TNF $\alpha$ therapy: results from the COIN study. Gut 2014;63:72-9.

18 Canadian Institute for Health Information. Prescribed Drug Spending in Canada, 2018: A Focus on Public Drug Programs. Ottawa, ON: CIH/ln: 2018 https://secure.cihi. ca/free_products/pdex-report-2018-en-web.pdf.

$19 \mathrm{Ng} \mathrm{SC}$, Shi HY, Hamidi N, et al. Worldwide incidence and prevalence of inflammatory bowel disease in the 21st century: a systematic review of population-based studies. Lancet 2018;390.

20 Kuenzig E, Benchimol El, Lee L, et al. The Impact of Inflammatory Bowel Disease in Canada 2018: Direct Costs and Health Services Utilization. In Press, 2018.

21 The Ontario Ministry of Health and Long-Term Care: The Ontario Drug Benefits Program. 2015. Available at http://www.health.gov.on.ca/en/public/programs/drugs/ programs/odb/odb.aspx.

22 About ICES Research. http://www.ices.on.ca/Research/About-ICES-Research 2015.

23 Benchimol El, Guttmann A, Mack DR, et al. Validation of international algorithms to identify adults with inflammatory bowel disease in health administrative data from Ontario, Canada. J Clin Epidemiol 2014;67:887-96.

24 Benchimol El, Guttmann A, Griffiths AM, et al. Increasing incidence of paediatric inflammatory bowel disease in Ontario, Canada: evidence from health administrative data. Gut 2009;58:1490-7.

25 Juurlink D, Preyra C, Croxford R, et al. Canadian Institute for Health Information Discharge Abstract Database: A validation study. Toronto Institute for Clinical Evaluative Sciences 2006.

26 Health canada notice of compliance search. 2016 https://health-products.canada.ca/ noc-ac/index-eng.jsp.

27 Ma C, Crespin M, Proulx MC, et al. Postoperative complications following colectomy for ulcerative colitis: a validation study. BMC Gastroenterol 2012;12:39.

28 Ma C, Moran GW, Benchimol El, et al. Surgical Rates for Crohn's Disease are Decreasing: A Population-Based Time Trend Analysis and Validation Study. Am J Gastroenterol 2017;112:1840-8.

29 Colombel JF, Sandborn WJ, Reinisch W, et al. Infliximab, Azathioprine, or Combination Therapy for Crohn's Disease. N Engl J Med Overseas Ed 2010;362:1383-95.

30 Cosnes J, Cattan S, Blain A, et al. Long-term evolution of disease behavior of Crohn's disease. Inflamm Bowel Dis 2002;8:244-50.

31 Pariente B, Cosnes J, Danese S, et al. Development of the Crohn's disease digestive damage score, the Lémann score. Inflamm Bowel Dis 2011;17:1415-22.

32 Feagan BG, McDonald JW, Panaccione R, et al. Methotrexate in combination with infliximab is no more effective than infliximab alone in patients with Crohn's disease. Gastroenterology 2014;146:681-8.

33 Panaccione R, Ghosh S, Middleton S, et al. Combination therapy with infliximab and azathioprine is superior to monotherapy with either agent in ulcerative colitis. Gastroenterology 2014;146:392-400.

34 Targownik LE, Benchimol El, Bernstein CN, et al. Upfront Combination Therapy, Compared with Monotherapy, for Patients Not Previously Treated with a Biologic Agent Associates With Reduced Risk of Inflammatory Bowel Disease-related Complications in a Population-based Cohort Study. Clin Gastroenterol Hepatol 2018.

35 Khanna R, Bressler B, Levesque BG, et al. Early combined immunosuppression for the management of Crohn's disease (REACT): a cluster randomised controlled trial. Lancet 2015:386:1825-34.

36 Khanna R, Sattin BD, Afif W, et al. Review article: a clinician's guide for therapeutic drug monitoring of infliximab in inflammatory bowel disease. Aliment Pharmacol Ther 2013;38:447-59

37 Bouguen G, Levesque BG, Pola S, et al. Endoscopic assessment and treating to target increase the likelihood of mucosal healing in patients with Crohn's disease 5. ClinGastroenterolHepatol 2014;12:978-85.

38 Colombel JF, Panaccione R, Bossuyt P, et al. Effect of tight control management on Crohn's disease (CALM): a multicentre, randomised, controlled phase 3 trial. Lancet 2018;390:2779-89.

39 Reich KM, Chang HJ, Rezaie A, et al. The incidence rate of colectomy for medically refractory ulcerative colitis has declined in parallel with increasing anti-TNF use: a time-trend study. Aliment Pharmacol Ther 2014;40:629-38.

40 Kaplan GG, Seow CH, Ghosh S, et al. Decreasing colectomy rates for ulcerative colitis: a population-based time trend study. Am J Gastroenterol 2012;107:1879-87.

41 Moore SE, McGrail KM, Peterson S, et al. Infliximab in ulcerative colitis: the impact of preoperative treatment on rates of colectomy and prescribing practices in the province of British Columbia, Canada. Dis Colon Rectum 2014;57:83-90.

42 Jandoc R, Burden AM, Mamdani M, et al. Interrupted time series analysis in drug utilization research is increasing: systematic review and recommendations. J Clin Epidemiol 2015;68:950-6.

43 Wagner AK, Soumerai SB, Zhang F, et al. Segmented regression analysis of interrupted time series studies in medication use research. J Clin Pharm Ther 2002;27:299-309.

44 Bernal JL, Cummins S, Gasparrini A. Interrupted time series regression for the evaluation of public health interventions: a tutorial. Int J Epidemiol 2017:46:348-55. 